\title{
ANNOUNCEMENTS
}

\section{THE AMERICAN ASSOCIATION FOR THORACIC SURGERY}

\section{The American Association for Thoracic Surgery Graham Traveling Fellowship, 2002-2003 STIPEND $\$ 75,000$}

$T^{\text {he }}$ he American Association for Thoracic Surgery Evarts A. Graham Memorial Traveling Fellowship was established in 1951 by The American Association for Thoracic Surgery. Administered through the Graham Educational Research Foundation Fellowship grants support study by young cardiothoracic surgeons from outside North America at sites of their choice within North America and include travel between sites. Goals of the program are to broaden overall training and increase international contacts. Each Fellow should plan to have one primary center for his/her activities where he/she should spend from six to nine months. The Fellow should have identified an individual at that center who will act as his/her sponsor and assist in planning the course of study at the host institution and at other institutions. In addition to the primary center, the Fellow is encouraged to plan to spend shorter periods of time at other secondary centers to enhance the Fellowship experience.

Awards are made to surgeons of unique promise who have been regarded as having the potential for later international thoracic surgical leadership. Since the inception of the Graham Fellowship, 48 young surgeons from 25 countries have completed the Fellowship.

The Fellowship provides a stipend of $\$ 75,000$, a major portion of which is intended for traveling expenses incurred when visiting other medical centers. The Fellowship also provides two round-trip coach air fares from the recipient's country to his/her primary center. The dates of the beginning and ending of the Fellowship year should be scheduled to coincide with the Annual Meeting of The American Association for Thoracic Surgery in May 2002. The Fellow will be introduced at this meeting and his/her predecessor will give a report of his/her year's experience to the Plenary Session. The Fellow will be expected to present a summary of his/her year's experience at the 2003 Annual Meeting, which will take place at the Hynes Convention Center, Boston, Massachusetts, May 4-7, 2003.

The Fellow should become involved predominantly with observation, consultation, teaching, and research at a variety of thoracic surgical training centers during the twelve months. Patient contact will be determined by the sponsoring surgeon and will conform to the regulations and licensing requirements of the state, province, or country in which he/she is studying. A candidate should have completed his/her formal training in general surgery and in thoracic and cardiovascular surgery, but he/she should not have reached a senior position. Candidates must be sufficiently proficient in English to realize the full benefits of the Fellowship. Candidates should not have received significant training in North America prior to making application for this award.

Applications for the Fellowship are available from:

Tirone E. David, MD, President

Graham Education and Research Foundation

Thirteen Elm Street

Manchester, MA 01944-1314

USA

Telephone 978-526-8330; fax 978-526-4018

Applications may be downloaded from the AATS Web site at: http://www.aats.org/doc/4939.

Completed applications must be returned no later than July 1, 2001. The selected candidate will be notified by December 15, 2001. 